\title{
Building Trustworthy Digital Repositories: Theory and Implementation. Edited by Philip
} C. Bantin. Lanham, MD: Rowman \& Littlefield, 2016. 371 pp. Index. Softcover. $\$ 65.00$.

For more than two decades, groups and individuals from a variety of professions have contributed to the growing understanding of the process of maintaining, providing access to, and preserving electronic materials in all of their many forms. Through international standards, reference models, and theoretical and practical applications, a body of research and recommendations has formed to help define approaches to digital system design, both for "everyday business systems ... used to create and manage digital information [and] trustworthy repositories intended to preserve and manage such information for the future" (p. 219). However, despite the ubiquity of electronic materials and years of research and discussion, many aspects surrounding the implementation of systematic digital content management remain opaque, even for technical professionals.

"What is a Trustworthy Repository, and how will we know if a system can indeed be trusted to achieve what it claims?" (p. 1). Beginning with this basic question and systematically exploring the many facets that make up the answer, this book examines the specific features and functional activities that comprise a trusted digital repository (TDR). Combining theory, history, and real-world examples, this authoritative work will help users gain a better understanding of TDRs and, more important, how to bring this understanding into their current practice. Editor Philip Bantin has been involved in archives and electronic records for decades, including providing instruction on trustworthy digital repositories for over 15 years. With the publication of this book, Bantin achieves his stated goal of advancing the scholarly literature "on how to begin implementing a trustworthy repository" in a way suitable for both long-time professionals and people new to the field (p. xv). This book casts a wide net over all aspects of the topic, bringing together the views and experiences of more than 40 professionals from academic and cultural institutions, federal and state governments, and businesses in the United States, Canada, Europe, and Australia. Bantin provides a comprehensive approach that includes the theory and history of electronic records management (ERM), as well as practical applications for the various features of a TDR and the records preserved in it. In 10 chapters, the authors move from the establishment of the TDR and supporting framework of policies and management, through the life cycle of the records from ingest to disposition or preservation, and conclude with a look at the future of trustworthy systems. Each chapter contains a theory section and one to three case studies that present new approaches to some more commonly discussed topics, such as creating metadata and providing access to electronic holdings, while also addressing equally important but less prevalent topics like retention and disposition, audit trail data, and security.

Throughout the book, the authors do an excellent job of framing the content in the larger context of ERM over the last two decades. For example, Lisa Schmidt (Michigan State University) writes about the ingest process as "one of the most important steps in archiving digital material" (p. 78). With the recognition that there is "no real 
standard practice" for ingest activities, Schmidt describes over a dozen approaches through conceptual models and implementation projects (e.g., OAIS, PAIMAS, DCC, TAPER, Archivematica, and the Hydra Project) (pp. 79-83). In the chapter "Capturing Audit Trail Data," Daniel Noonan (The Ohio State University) traces the national and international history of electronic records standards from the US Department of Defense military standards to InterPARES; explores guidelines set out by the International Organization for Standardization (ISO), the European Commission's Model Requirements (MoReq), and ARMA International; and discusses the development of OAIS, TRAC, DRAMBORA, and other reference models and assessment frameworks (pp. 170-73). Lois Evans (University of British Columbia, InterPARES Trust) looks at many of these same approaches through the lens of repository security and provides "a review of security concepts and strategies, relevant models, and requirements” (p. 271).

The practical value of the book is borne out repeatedly through many examples of unique implementation projects. Despite their differences, the case studies adhere to a similar structure and include comparable information: context and background, strategies (methodologies and techniques) used, challenges encountered, results and outcomes, evaluation and analysis, and practical advice through lessons learned (p. xiv). For instance, the chapter "Creating an Access Strategy" contains three different approaches to what is essentially a similar problem: providing access to digital records. Debbie Bahn discusses the Washington State Archives' approach to automating different levels of access to government records through metadata and "a policy of flexibility and shared responsibility" between the archives and the record creators (p. 227), sharing practical details like project staff and workflow steps involved. Mary Beth Herkert provides a different perspective, describing the Oregon State Archives' process of implementing a statewide electronic records management system, focusing on bigger picture issues like marketing, "virtual hoarding," and the challenges that users struggle with, such as the "perception of loss of control" or feeling overwhelmed by unmanaged legacy data (pp. 243-46). Lorraine Richards recounts Drexel University's experience helping to define access requirements for the Federal Aviation Administration's scientific data repository through a holistic and iterative approach "whereby the development of an access plan is recognized to be a long-term, incremental and additive process" (p. 261), while working through the creators' misunderstandings (e.g., "believing that availability equals access") and concerns (e.g., data privacy and integrity) (pp. 257-59). Comparisons can also be made between chapters that have different foci, such as the Indiana Archives and Records Administration's exhaustive search for the best possible records management system, which contrasts nicely with the more flexible approach enacted by the Digital Archives at State Records New South Wales to selectively adopt standards and interchangeable tools as needed for metadata management.

These 10 chapters present the reader with a range of writing styles and project approaches, history and theory, and practical applications. Indeed, a large part of the book's success comes from its diversity. Whether contemplating the best approach to 
take on a given project or seeking to improve existing systems, the reader is certain to encounter thought-provoking and insightful writing. The structure of the book is well suited for a comprehensive dive into the world of TDRs, or for a more targeted review of any particular facet. A couple of key points at the heart of implementing a trustworthy digital repository come through repeatedly in a number of contexts: a) "it is a combination of the characteristics that brings trustworthiness" (p. 142), and b) "[it] is an ongoing process of refinement and revision" (p. 96).

As one final piece of evidence of the value of its contribution to the profession, this book earned Bantin the Society of American Archivists' Waldo Gifford Leland Award in May 2017 for "writing of superior excellence and usefulness in the field of archival history, theory, and practice." ${ }^{1}$ Regardless of where you are in the process of building a trusted digital repository, if you work with digital materials at any stage, or aspire to learn more about the processes and activities involved, this book contains a wealth of information and insights that will undoubtedly be of use and is highly recommended.

\author{
Erin Wolfe \\ Metadata Librarian \\ University of Kansas Libraries
}

\title{
NOTE
}

1. Society of American Archivists, "Waldo Gifford Leland Award," http://www2.archivists.org/ governance/handbook/section12-leland. 